\title{
Why Epistemic Reductionism Won't Save the Moral Error Theorist
}

\author{
Alex Murphy ${ }^{1}$ (iD \\ Accepted: 6 January 2020 / Published online: 21 January 2020 \\ (C) The Author(s) 2020
}

\begin{abstract}
Moral error theorists often respond to the epistemic companions in guilt strategy by adopting the Disparity Response: reject the putative parity between moral and epistemic reasons and claim that though the former are irreducibly normative, the latter aren't. I argue such a response fails. Expanding on Das' Australas J Philos 95(1):58-69, (2017) work I present a master argument against Disparity Responses: the arguments moral error theorists use to advance their conceptual claim apply in the epistemic domain also. This prohibits the error theorist from adopting epistemic reductionism. I use Jonas Olson's work as exemplary of moral error theory. I demonstrate that Olson's (2014) argument that the rhetorical authority of moral claims is best explained by the error theorist's conceptual claim applies equally in the epistemic case. Olson (2018) attempts to avoid this by claiming that epistemic claims are reducible to claims about whether our doxastic attitudes live up to their functions. There are two problems with Olson's (2018) argument. Firstly, functional reasons are a species of a common genus - standards reasons - and since Olson's authority argument against moral reductionism applies to standards reasons, it applies to functional reasons. Secondly, Olson's (2018) claim that we cannot also cast moral reasons as functional is under-supported. I suggest that there is plausible evidence that we can and undermine his arguments against this claim. I do not argue that the epistemic companions in guilt strategy demonstrates the falsity of moral error theory. Rather, I argue that the Disparity Response to the epistemic companions in guilt strategy fails.
\end{abstract}

Keywords Moral error theory $\cdot$ Epistemic error theory $\cdot$ Moral reductionism $\cdot$ Epistemic reductionism $\cdot$ Meta-ethics $\cdot$ Meta-epistemology $\cdot$ Meta-normativity

Alex Murphy

alexmurphy111@googlemail.com

1 University of Cambridge, Raised Faculty Building, Sidgwick Avenue, Cambridge CB3 9DA, UK 


\section{Introduction}

Moral error theory is the view that our everyday moral discourse commits us to the existence of irreducibly normative reasons but that since there are no such things, our discourse is systematically mistaken. ${ }^{1} \mathrm{~J}$. L. Mackie claimed that the most effective response to moral error theory would be to introduce "companions in guilt." 2 One prominent companion discussed in recent years has been epistemic reasons, leading to the epistemic companions in guilt strategy. ${ }^{3}$ This strategy attempts to lend credibility to moral reasons by demonstrating their similarity to epistemic reasons whose existence we should not reject. One way to dismiss this strategy is to reject the parity and claim that though moral reasons are irreducibly normative, epistemic reasons are not. Call this the Disparity Response to the epistemic companions in guilt strategy.

Moral error theorists argue for the conceptual part of their view by claiming that the best explanation for the apparent authority of our moral discourse is that our common-sense conception of moral discourse implies that moral judgements are irreducibly normative. ${ }^{4}$ These arguments apply equally, however, to our epistemic discourse. If they show that we take our moral claims to be irreducibly normative, then they do so for our epistemic claims too. The error theorist's own arguments deny her the Disparity Response. This is the master argument against the Disparity Response. ${ }^{5}$

There are two ways to respond to this argument. The first is to find a profile for epistemic reasons which makes them immune from the arguments moral error theorists use to support the conceptual claim. The second is to find more fine-grained arguments for the conceptual claim that only apply to moral reasons.

I demonstrate the potency of the master argument by using Jonas Olson's work as exemplary of moral error theory. ${ }^{6}$ The difficulties facing Olson illustrate a general tension in the combination of moral error theory and epistemic reductionism. Olson (2018) adopts the first response to the master argument. I argue that this fails.

In §2-3 I make some preliminary remarks, introduce some terms and distinctions and explain the dialectical background to, and motivation for, this discussion. In $\S 4$ I discuss Olson's move towards the Disparity Response. In §5-8 I discuss the parity between moral and epistemic reasons and reject Olson's (2018) disparity response. I present the master argument against the Disparity Response in $\S 9$.

\section{Preliminaries}

Firstly, a note on reasons. I follow contemporary orthodoxy in supposing that if there are any primitive normative concepts, then the concept of a reason is the only one. ${ }^{7}$ I additionally

\footnotetext{
${ }^{1}$ This is the particular kind of moral error theory that concerns me here.

2 (1990/1977, p.39). Interestingly, Mackie discusses error theory first in his (1946).

${ }^{3}$ Especially after Cuneo (2007).

${ }^{4}$ That this is the common-sense conception does not require that people understand or use terms such as 'irreducibly normative.'

${ }^{5}$ Inspired by Das (2017).

6 (2011, 2014, 2018).

7 This orthodoxy is established by authors like Scanlon (1998) and Parfit (2011). See Broome (2013) and Manne (2014) for alternatives. My argument need not depend on reasons primitivism of the sort stated, I adopt it for dialectical ease of presentation.
} 
accept the common assumption that normative reasons are facts, ${ }^{8}$ and that they stand in favouring relations to courses of behaviour. ${ }^{9}$

Secondly, a notion that plays a key role in this literature is metaphysical queerness. The idea that moral reasons are queer is presented, by error theorists, as reason to think they do not exist. What it is for an entity to be queer in the relevant way is not our concern. It is what makes moral reasons queer that interests us. There is debate on this, but the kind of error theory considered here claims it is their irreducible normativity. ${ }^{10} \mathrm{~A}$ reason is irreducibly normative iff the favouring relation, in which it stands to the relevant behaviour, is irreducibly normative - i.e. cannot be described (or analysed) in purely descriptive terms. There is no conceptual space to ask whether an irreducibly normative reason should be a consideration for us; it simply is. A reason is categorical iff it is irreducibly normative.

\section{The Problem}

The problem we are concerned with begins with linguistic phenomena in need of explanation. We say things about what we, individually or collectively, should do - what we have reason to do. ${ }^{11}$ This includes claims about both how we should act and what we should believe (and why). Following Cuneo (2016) let us call sentences which incorporate paradigmatically moral terms such as 'wrong', 'obligatory', 'fair' etc. in the predicate position moral sentences. Call commonplace, and sincere, uses of such sentences our everyday moral discourse. Similarly, sentences that incorporate paradigmatically epistemic terms such as 'rational', 'warranted' or 'justified' in the predicate position are epistemic sentences and commonplace, and sincere, uses of such sentences constitutes our everyday epistemic discourse. ${ }^{12}$ Our everyday moral and epistemic discourse needs explanation in two senses. Firstly, we need an explanation of what we think we are doing when we utter moral/epistemic sentences. Secondly, we need an explanation of whether we are successful.

The first explanandum requires an exploration of our common-sense conception of these discourses. Cuneo (2007) suggests that our common-sense conception is constituted by platitudes of two sorts - content and authority.

The content platitudes state that any non-deviant moral or epistemic system must involve substantive propositions like the following: $<$ It is wrong to kill recreationally $>$ or $<$ It is wrong to disregard evidence out of laziness $>$. The content platitudes roughly delineate the norms that feature in our common-sense conception of proper moral/epistemic practice.

The authority platitudes concern the normative force of moral and epistemic facts - if there are any. They tell us that moral and epistemic facts have two features. Firstly, they are prescriptive - they indicate reasons for us to behave in certain ways. Secondly, they are authoritative - the reasons that they indicate are irreducibly normative.

With respect to the second explanandum, I concern myself with two positions. The first is error theory which has two stages:

\footnotetext{
${ }^{8}$ For a discussion of this see Glüer-Pagin and Wikforss (2017).

${ }^{9}$ Like Olson (2014) I understand 'behaviour' broadly - including doxastic behaviour like forming beliefs. For exemplar formulations of the favouring relation - Bedke (2010, p.48) or Cuneo (2007, p.65).

${ }^{10}$ For an example of such debate compare Brink (1984) and Garner (1990).

${ }^{11}$ In addition, there are mental phenomena - we think things about what we should do. Arguments for the conceptual claim tend to focus on the linguistic phenomena and therefore so do I.

12 These are intended as working definitions.
} 
1. Conceptual: Our everyday moral discourse involves commitment to the irreducible normativity of moral reasons.

2. Ontological: There are no irreducibly normative reasons.

The conceptual claim affirms commitment to the authority platitudes. When this is combined with the ontological claim (2) the result is that our moral discourse (and thought) is systematically erroneous. Moral discourse attempts to represent irreducible moral reasons but since there are no such things, it is erroneous. Epistemic error theory is an epistemic analogue of moral error theory, holding that our epistemic discourse commits the same systematic ontological error. This is the form of error theory Olson proposes and, since I use his work as exemplary, it is the form I engage with. ${ }^{13}$

The second is reductionism. ${ }^{14}$ Moral reductionism is the view that moral reasons exist and are reducibly normative. As Cuneo (2007) points out, reductionist accounts reject the authority platitudes. ${ }^{15}$ Epistemic reductionism is an epistemic analogue of moral reductionism.

Error theory and reductionism differ in that the former views our talk, and thought, of reasons as regarding irreducibly normative reasons whereas the latter does not. ${ }^{16}$ The view that concerns me here is the combination of moral error theory and epistemic reductionism. This combination is of dialectical interest because it is used as a response to the epistemic companions in guilt strategy.

The epistemic companions in guilt strategy attempts to defend the credentials of moral reasons by establishing a parity with epistemic reasons. The problematic feature of both is that they are irreducibly normative. The argument runs as follows:

1. Parity Premise: If the arguments for moral error theory establish its truth, then they (or relevant analogues) establish epistemic error theory.

2. Epistemic Existence Premise: Epistemic error theory is false.

3. Conclusion: Arguments for moral error theory do not establish the truth of moral error theory. ${ }^{17}$

One rejoinder to this argument is the Disparity Response: reject the Parity Premise and claim that though moral reasons are irreducible, epistemic reasons aren't.

I argue that this response is unsatisfactory. Prima facie evidence for the Parity Premise shows that those who wish to reject it are required to provide arguments for doing so. Moral error theorists cannot provide such arguments without contradicting their support for the conceptual claim.

I do not claim to show that the error theorist cannot escape or defuse the epistemic companions in guilt strategy, but only that this attempt at doing so fails. The error theorist

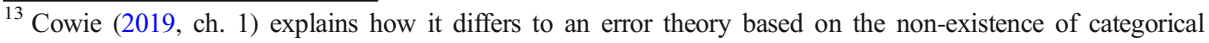
reasons.

${ }^{14} \mathrm{I}$ have in mind unobvious analytic reductionism, knowable a priori, though my argument doesn't rely on this.

${ }^{15}$ One might object that metaphysical reductionism about moral/epistemic reasons is consistent with the view that our common-sense conception includes the authority platitudes. This, however, would be an error theory (though not the one that concerns us). It would be the view that when discussing moral/epistemic issues we are not only ontologically mistaken but also semantically mistaken in that it refers to something other than what was intended. I therefore do not consider this position a form of reductionism.

${ }_{16}$ As Das puts it, the difference "concerns the conceptual profile of...reasons" (2017, p.58).

${ }^{17}$ Cowie's (2014) formulation.
} 
may choose to reject the Epistemic Existence premise. ${ }^{18}$ This is a radical and intuitively unattractive position however. ${ }^{19}$ We should take the epistemic companions in guilt argument seriously. Figure 1. maps out the relevant conceptual space:

\section{Reducible Reasons and Olson's Move to the Disparity Response}

Olson defends an error theory regarding irreducibly normative favouring relations; his work provides an informative case study because of his recent shift towards the Disparity Response.

Previously Olson (2014) conceded the Parity Premise and defended both moral and epistemic error theory. He argued that the consequences of accepting epistemic error theory are not as undesirable as they seem. In this response Olson presents a distinction relevant to our current concerns.

Olson (2014) claimed that 'reason' is equivocal between an irreducible and reducible sense. He countenances two types of reducible reasons: hypothetical and conventional reasons. ${ }^{20}$ To say that some agent, A, has hypothetical reason to $\mathrm{p}$ is to say that A has some goal/desire which would be (likely) fulfilled were she to p. Hypothetical reasons are understood as reducible to empirical claims about the agent's desires and means of bringing about their satisfaction. $^{21}$

Conventional reasons are reducible to claims about what is in accordance with, or in violation of, conventions. For example, according to the rules of soccer, outfield players are prohibited from using their hands to control the ball. This gives Lionel Messi a conventional reason not to use his hand whilst playing. This reduces to the claim that doing so would be in violation of the rules of soccer.

A reductionist is hypotheticalist or conventionalist depending on whether they claim that the relevant reasons are hypothetical or conventional. Note that, reducible reasons only apply to those who meet certain conditions - having the relevant desires or engaging in the relevant activity.

Olson's (2018) response to the epistemic companions in guilt strategy is different. Though Olson still believes that the consequences for holding epistemic error theory are not as undesirable as Cuneo suggests, he leaves this to one side. He favours epistemic reductionism, over epistemic error theory, but remains a moral error theorist. As such he adopts the Disparity Response. I shall show that Olson's (2018) response fails and extract a master argument against the Disparity Response from it.

\section{Prima Facie Support for the Parity Premise}

To set the scene for the master argument I shall establish that there is prima facie evidence in favour of the Parity Premise. The burden of proof, therefore, lies with those who wish to reject it.

\footnotetext{
${ }^{18}$ E.g. Streumer (2017) endorses meta-normative error theory.

${ }^{19}$ See Cuneo (2007, p.117-120).

${ }^{20}$ Olson calls conventional reasons "reasons reducible to correctness norms" (2014, p.159), my use of "conventional reasons' is to avoid confusion in later sections.

${ }^{21}$ This interpretation is contested. My interpretation is more stringent than Joyce's (2001, p.122). Furthermore, Bedke (2010) claims that hypothetical reasons are irreducibly normative.
} 


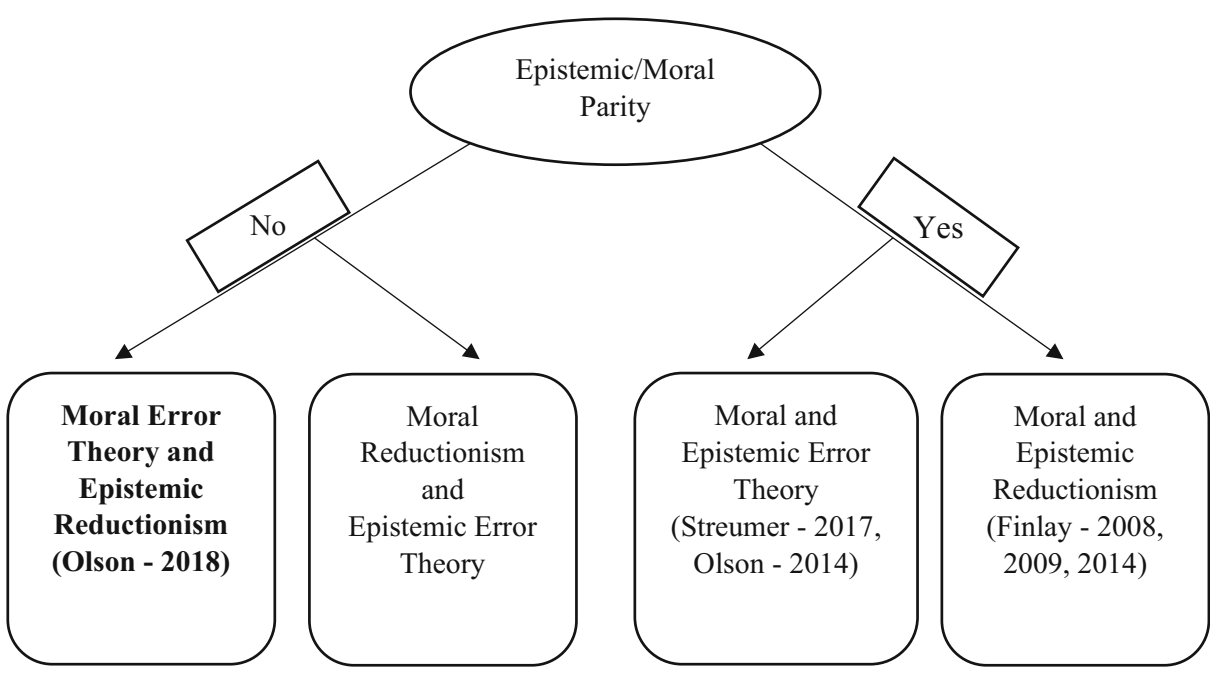

Fig. 1 Mapping the relevant positions

There are many different considerations in favour of the Parity Premise. I present here the two that I find most convincing. ${ }^{22}$ The first is that both epistemic and moral reasons seem to be categorical - they seem to apply to us independently of our desires and commitments in a way that marks them as irreducibly normative. Consider two paradigmatic cases of an agent having a reason. First, an epistemic example:

Train: I look at the departure board. It says that my train leaves at 0825 . Surely this evidential consideration is a normative reason for me to believe that the train leaves at $0825 \ldots$ whether or not I want to believe that my train leaves at 0825 . So, the normative reason is.... categorical. $^{23}$

Contrast this to the following example of an agent having a moral reason:

Help: I see a child struggling to swim in a pond. Nobody else is around and she will die if nobody intervenes. This fact is a normative reason for me to save her and surely this is so, whether or not I want to save her. So, the normative reason is categorical.

In both these cases it seems that the relevant reason is categorical - it applies independently of my desires or commitments. Consider the following two conversations as further evidence. First the epistemic case:

\section{Fanatic:}

A: 'You should believe the theory of evolution.'

B: 'Why?'

A: 'There is more evidence for it than for competing theories.'

B: 'I don't care about evidence.'

A: 'That doesn't matter, you still should believe the theory of evolution!'

Second, the moral case:

\footnotetext{
22 For others - Kearns and Star (2009, p.220-22).

${ }^{23}$ Cowie (2016, p.117).
} 


\section{Liar:}

A: 'You should not have lied!'

B: 'Why not?'

A: 'Lying is morally wrong.'

B: 'I don't care about morality.'

A: 'That doesn't matter, you still shouldn't have lied!'

In both cases A's final response suggests that the relevant reason is categorical. It doesn't matter what desires or commitments B has, the reasons still intuitively apply. In both sets of examples, epistemic and moral reasons seem to mirror each other. That both moral and epistemic reasons seem to be categorical suggests that they are both irreducibly normative. ${ }^{24}$

The second consideration in support of the Parity Premise is the structural isomorphism between moral and epistemic reasons. Cuneo (2007) observes that moral and epistemic reasons share what he labels appraisable entities and modes of response.

Starting with the former, our normative appraisal gives rise to reasons to adopt certain courses of behaviour. Let us call any entity that is open to moral assessment a morally appraisable entity - analogously in the epistemic case. There is vast overlap between morally and epistemically appraisable entities. It is not simply that moral appraisals apply to actions and intentions whereas epistemic appraisals apply to beliefs. Rather they both apply to a wide range of entities - institutions, persons, intentions, actions, propositional attitudes, emotions, character traits, etc.

Let us use the term 'mode of response' to refer to the sorts of responses that reasons favour. For instance, a reason may favour the formation of a propositional attitude or the execution of an action. Cuneo points out that there will be significant overlap between the class of all and only the modes of response moral reasons favour, and the analogous epistemic class. It is not the case that moral reasons favour only the formation of intentions and the execution of actions whereas epistemic reasons favour only the formation of propositional attitudes. Rather epistemic and moral reasons, respectively, favour all sorts of responses.

We can reformulate Cuneo's observation as follows - consider the following schema (where $\mathrm{X}$ is an appraisable entity and $\mathrm{Y}$ a mode of response):

The moral/epistemic appraisal of $\mathrm{X}$ gives rise to a moral/epistemic reason to $\mathrm{Y}$.

Moral appraisal gives rise to moral reasons, epistemic appraisal gives rise to epistemic reasons. Cuneo is pointing out that we shouldn't think a certain kind of entity should replace X and Y when considering moral reasons but a different kind should when considering epistemic reasons.

Consider the following examples. The first pairs a moral reason with an appraisable entity and mode of response which appear better suited to an epistemic reason:

Example 1: Gemma's belief that her son is missing gives her a moral reason to hope that he is still alive.

\footnotetext{
${ }^{24}$ It may be objected that one can derive different conversational evidence in the epistemic case. For example, it may be implausible that A would respond to B in such a way if they were discussing B's putative reason to believe a trivial truth. I put this aside noting that such a case should be considered an exception and does not undermine the prima facie evidence presented here. For discussion of this issue consult Cowie (2019) as well as Adam Leite and Thomas Kelly's discussion of epistemic instrumentalism - Kelly (2003, 2007) and Leite (2007).
} 
The second pairs an epistemic reason with an appraisable entity and mode of response which appear better suited to a moral reason.

Example 2: Gemma's intention to help Gary through his trauma gives her an epistemic reason to call his friend and discuss how to do so.

Some moral reasons can be theoretical and some epistemic reasons practical. It seems strange to suggest that one type is irreducible whereas the other is not.

It may be objected that these considerations apply equally to paradigmatically hypothetical reasons - namely prudential reasons. ${ }^{25}$ Regarding the fact that we speak about moral and epistemic reasons as if they are categorical (the first consideration) it might be pointed out that parallel data can be generated for prudential reasons. Consider:

\section{Smoker:}

A: 'You shouldn't smoke.'

B: 'Why not? Smoking is great!'

A: 'It makes your teeth yellow.'

B: 'I don't care.'

A: 'That doesn't matter, you still shouldn't smoke!'

The objector may claim that this is a cogent exchange, yet it doesn't speak in favour of the claim: if moral reasons are categorical, then so are prudential reasons. ${ }^{26}$

Regarding the fact that moral and epistemic reasons share appraisable entities and modes of response (the second consideration) one may point out that moral reasons share both appraisable entities and modes of response with prudential reasons. Actions (and propositional attitudes) can be both morally and prudentially (in)advisable. Both moral and prudential reasons may license a range of responses.

To this objection I give two responses. Firstly, these considerations are presented only as prima facie evidence for the Parity Premise. Secondly, it is not clear that prudential reasons are paradigmatically hypothetical. ${ }^{27}$ As far as these considerations go, there is a prima facie case for the irreducibility of prudential reasons. This data suggests that we should carefully consider our view on prudential reasons.

\section{Olson's Attack on Finlay - a Double Edged Sword}

Having provided prima facie support for the Parity Premise, I now look to Ramon Das' (2017) work demonstrating that Olson's authority argument against moral reductionism applies equally in the epistemic domain. ${ }^{28}$ The authority argument is representative of Olson's arguments for the conceptual claim. This provides me with the resources to both combat Olson's (2018) argument against the Parity Premise (\$8) and formulate a master argument against the Disparity Response ( $\$ 9)$.

Since Olson is a moral error theorist, he is committed to the authority platitudes. This leads Olson $(2011,2014)$ to criticise Stephen Finlay's $(2008,2009,2014)$ end-relational account of

\footnotetext{
$\overline{25}$ Thank you to an anonymous reader for this suggestion.

${ }^{26}$ Note, one could claim that A's final response is unintuitive. I put this response aside since it feels less appropriate if, for example, A was noting the serious physical harm smoking does.

${ }^{27}$ See Fletcher (2018, forthcoming).

28 'Authority argument' is my label rather than Olson's.
} 
moral terms and reductionism regarding moral reasons. Das has argued that Olson's objections against Finlay apply equally well in the epistemic case and that therefore Olson, by his own lights, should also view epistemic reasons as irreducibly normative. It is not the success or failure of Olson's objections to Finlay's account that is of primary importance here. Rather it is their equal applicability in the moral and epistemic domains. As I shall demonstrate in $\S 9$, this makes it difficult for moral error theorists to reject the Parity Premise. ${ }^{29}$

Finlay is a reductionist about normative reasons (and a fortiori about moral reasons). He presents an end-relational semantics of our moral terms, claiming that our use of language is not evidence that we understand moral reasons as irreducibly normative. For Finlay, all reasons are relative to some end. The relevant ends are not merely desires, Finlay's account accommodates reducible reasons of all sorts. ${ }^{30}$ Normative reasons are understood as probabilistic explanations why something is good - relative to some end:

'a reason for s to $\phi$ ' is used as elliptical for 'a reason [why it's good] for s to $\phi$ ', and means an explanation why it's good if $s \phi s^{31}$

Olson objects that Finlay's account is not the best explanation of the apparent authority of our moral discourse. ${ }^{32}$ Call this the authority argument. He starts by noting that cases of moral disagreement are evidence for the conceptual claim of moral error theory. In such cases we pursue moral arguments, sometimes with people who have different fundamental moral values to us. This suggests that we take moral reasons to apply even to those who have differing goals and commitments. Finlay's account must provide an alternative explanation for this phenomenon.

Finlay tries to undermine this evidence by claiming that in cases where there is disagreement, our attempts to convince each other should be understood pragmatically. ${ }^{33}$ Our moral claims have pragmatic authority. They can be considered successful if they motivate others to comply with our ends. We withhold the relative ends of our moral judgements to achieve this. By withholding the relative ends from moral utterances, speakers speak as if something were true of the audience (namely that they share the withheld end). ${ }^{34}$ The effect is that the speaker expresses a prescription demanding that the audience share the withheld end. For example, by omitting 'according to end e' from the claim '... .you shouldn't steal that purse' I give rhetorical authority to the claim. This is an attempt to motivate you to comply with my ends - it is a rhetorical tool. The idea is that "pragmatically categorical use of normative language...[is] a particularly effective way of exerting strong prescriptive force on an agent.",35

Contra this pragmatics-first approach, Olson believes that the rhetorical force of our moral claims is best explained by their semantics. Olson writes that "moral claims have rhetorical force because they are or entail claims about irreducibly normative reasons." 36 He asks us to consider two claims:

\footnotetext{
${ }^{29}$ Rowland (2013,p.4-5) noted a similar tension between hypotheticalist epistemic reductionism and moral error theory. I show that it applies to all forms of reductionism.

${ }^{30}$ Consequently, arguments against it apply to reducible reasons of all forms.

31 (2014, p.94).

32 Das (2017) also considers an argument Joyce (2001) presents against Finlay which is similar to the authority argument.

${ }^{33}$ Finlay (2014, Ch. 8).

${ }^{34}$ To speak as if agents share an end is to make utterances that would be co-operative, in the Gricean sense, were it the case that the end is shared.

35 (Finlay 2014, p.187).

36 (2014, p.129).
} 
Tax: 'It is morally wrong to cheat on your tax declaration.'

Spoon: 'It is bad manners to eat peas with a spoon.'

Both Spoon and Tax are, according to Finlay, relativized to a withheld end. Yet Tax has greater rhetorical force than Spoon. Finlay's explanation for this discrepancy is that moral ends are of greater concern to us and so we are more serious about our moral appraisals than our appraisals regarding etiquette. Olson objects that "one would expect the difference in seriousness and intransigence between moral... and etiquette claims to be reflected in the concepts we use to make them. The conceptual claim makes good on this expectation.",37

Furthermore, Olson adds that it is hard to see how moral claims could maintain their greater rhetorical force if they shared conceptual status with etiquette claims. If Finlay is correct, then someone who doesn't care about the relevant end could waive Tax just as easily as they could waive Spoon. Yet this is intuitively not the case, and the conceptual claim gives a good explanation as to why - moral claims are irreducibly normative, etiquette claims are not. Olson applies this criticism to both hypotheticalist and conventionalist moral reductionism. ${ }^{38}$

Overall, Olson claims that it is implausible that the authority of our moral claims is purely a pragmatic matter. The crucial point is that Olson's argument applies equally well in the epistemic domain. ${ }^{39}$ Consider a third claim:

Alien: 'It is irrational to believe that Tony Blair is an alien.'

Olson's complaint against Finlay was that an end-relational semantics, with a focus on pragmatics, fails to capture the authority of our moral judgements. Yet the same goes for our epistemic judgements. If Alien was relativized to a (withheld) end, and we thought of it as such, then we would expect the rhetorical force of Alien to match that of Spoon. Yet Alien has greater rhetorical force than Spoon. Furthermore, Alien would fail to retain its greater rhetorical force if it were implicitly relative. This is so for the aforementioned reason - from the perspective of someone who doesn't care for the relevant ends Alien would be as easy to waive as Spoon.

Independently of how powerful Olson's objection is, the crucial point is this: if Olson's argument shows that our moral discourse is best explained by an account which incorporates the conceptual claim, then it does so regarding our epistemic discourse as well. Olson (2018) attempts to avoid this conclusion.

\section{Olson's (Not So) New Form of Reducible Reason}

Olson (2018) holds that epistemic reasons are reducible. Interestingly, however, he claims that they are neither conventional, nor hypothetical. Olson uses this as the basis for an argument against the Parity Premise. If these new reducible reasons are relevantly different, then Olson can claim that they are not threatened by the authority argument. Olson is adopting the first of the two retorts on behalf of Disparity Responses. Combined with Olson's argument that there are no corresponding moral reasons of the same type, this yields a successful Disparity Response.

Olson focuses on something that, at first, seems peculiar to the epistemic domain - the truth norm of belief. One intuitive feature of belief is that it 'aims at truth'. As Williams (2004)

\footnotetext{
37 (Ibid).

${ }^{38}$ Olson (2014, p.129-3).

${ }^{39}$ As Das (2017) pointed out.
} 
explains, the idea is that it is a fatal objection to a belief that it is false. If someone accepts that a belief is false they thereby cease to have the belief (consciously). Recognising the falsity of one's belief is enough to abandon it. This is usually seen as evidence that epistemic reasons are irreducibly normative because it implies that the very practice of believing is regulated by a norm. Olson takes what looks to be an enemy of epistemic reductionism and turns it into an ally.

Olson claims that "the cognitive capacity of belief formation has a characteristic aim or function" in a similar way to the heart. ${ }^{40}$ This function is to "help subjects navigate and explain the world that they find themselves in, by carrying correct...information about subjects' surroundings." ${ }^{21}$ For a belief to fulfil its function properly it must be formed in accordance with the appropriate epistemic norms. We can thus say that a belief is well-formed, given the function of belief, if it is, for example, based on evidence. Olson gives the following definition:

for a consideration, $\mathrm{E}$, to be an epistemic reason for an agent to believe that $\mathrm{p}$ is for it to be the case that were the agent to believe that $\mathrm{p}$ on the basis of $\mathrm{E}$, the agent's belief that $\mathrm{p}$ would be, to that extent, well-formed, or as it ought functionally to be. ${ }^{42}$

Epistemic reasons are reducible because it is an open question whether it "ought to be that the entity fulfils that function or whether there are reasons for agents to ensure that...[it does]." ${ }^{, 43}$ Similarly, it is an open question whether Messi should engage in the activity of soccer, where doing so makes various conventional reasons apply to him. It is not an open question whether irreducible reasons apply. On this account, error theorists about irreducibly normative reasons can claim that there is a truth norm governing belief since this is "simply to say that a cognitive system in which individual beliefs are based on evidence [for example] is, to that extent, well-functioning.",44

For this understanding of epistemic reasons to be useful to Olson in building a disparity response it must not have a moral analogue. Moral error theorists do discuss the function of morality however (my italics):

...part of the reason why moral thought and talk evolved is their coordinating and regulative functions that are highly useful from an evolutionary perspective. ${ }^{45}$

The function of morality is primarily to counteract this limitation of men's sympathies. ${ }^{46}$

Morality, I will argue, functions to bolster self-control. ${ }^{47}$

Alert to this, Olson considers the potential for an analogous argument for the reducibility of moral reasons. The idea would be that moral judgements (qua moral judgements) have a characteristic function(s) which support the view that moral reasons are reducibly normative. Olson claims that this analogy fails and that a disparity holds between epistemic and moral reasons. He argues that though the function of belief supports a particular view of reasons for belief, "it is not clear how a view of the characteristic function of moral judgements could support any kind of view of moral reasons - a category that includes reasons for actions and reason for attitudes other than [and including] belief - and not just a view of reasons for moral judgements." 48

\footnotetext{
${ }^{40}$ Olson (2018, p.12).

41 (ibid, p.13).

42 (Ibid, p.14).

43 (Ibid, p.14).

44 (Ibid, p.14).

45 Olson (2014, p.128).

${ }^{46}$ Mackie (1977/1990, p.108).

${ }^{47}$ Joyce (2001, p.181).

48 (2018, p.19).
} 
Furthermore, Olson adds that it is partly the irreducible normativity of our moral concepts which enables moral judgements to fulfil their functions of "promoting cooperation, solving coordination problems, and blocking weakness of will." 49

\section{Responding to Olson's New Suggestion}

Olson's disparity response has two parts:

1. Create a profile for epistemic reasons that makes them immune to his arguments against moral reductionism.

2. Show that moral reasons do not share this profile.

Correspondingly, I present two responses to Olson's new suggestion. I start by demonstrating that Olson's new account of epistemic reasons makes them a species of a genus - standards reasons. I then, as my first response, show that Olson's authority argument against moral reductionism applies to standards reasons and so to epistemic reasons as he has cast them. This objection targets the first half of Olson's disparity response and is an extension of Das' (2017) argument discussed above. My second response is to argue that an analogous account of moral reasons is conceivable and to question why it is less plausible than its epistemic analogue. This undermines the second half of Olson's disparity response. Overall, Olson's new account of epistemic reasons fails to demonstrate a disparity between epistemic and moral reasons.

Let us call reasons reducible to claims about the performance of an entity as compared to its function, functional reasons. Functional reasons are not, in any important sense, new or different. Conventional reasons and functional reasons are two species of a common genus: reasons reducible to claims about standards or, standards reasons. ${ }^{50}$

Consider how the reducibility of both conventional and functional reasons is demonstrated. In both cases we reduce these reason claims to descriptive claims matching performance to a standard, namely a standard which isn't compulsory. Consider the following:

1. Conventional: You shouldn't use your hands during a soccer game. This reduces to the claim: using your hands violates the rules (conventions) of soccer. Since this is a descriptive claim, the reason is reducible.

2. Functional: You should believe in accordance with evidence. On Olson's analysis this reduces to the claim: were you to believe in accordance with evidence, your beliefs would be well-formed according to their function. Since this is a descriptive claim, the reason is reducible.

For a belief to be well-formed according to its function is simply for it to match up to a certain set of standards. Central to the reducibility of both conventional and functional reasons is the notion of standards. Whether the standard is set by convention or by function is irrelevant. To demonstrate that the notion of a standards reason is not an empty catch-all for any type of reducible reason consider again hypothetical reasons.

\footnotetext{
49 (Ibid).

${ }^{50}$ My terminology departs from Olson's.
} 
3. Hypothetical: You should take the M11. This is understood as: If you desire to go to Cambridge, then you should take the M11. This reduces to: taking the M11 would further the satisfaction of your desire to get to Cambridge.

This cannot be understood as: the standards of your desires are such that taking the M11 would satisfy your desires. It is both unnatural and incorrect to say that the standards of your desires make it such that a certain action constitutes an effective means towards satisfying them. Rather it is the desires themselves. ${ }^{51}$

Having shown that functional reasons are standards reasons I now demonstrate that Olson's authority argument applies to standards reasons. Olson's argument against moral reductionism applies to conventional reasons because conventional reasons are a species of standards reason. It is the genus, rather than the species, which Olson's (2014) argument targets.

If moral or epistemic claims, such as Tax or Alien, were, in fact, claims about how certain courses of behaviour match up to certain standards, then they would lack the rhetorical strength that they intuitively have. This would be the case for the reason discussed above - if these claims reduce to claims about standards, ones which we are not obliged to adopt, then we can legitimately waive them if we do not care for these standards. If you didn't care for the relevant standards, then Tax or Alien would be just as easy to waive as Spoon. Intuitively, however, they are not. The intuitively stronger rhetorical force of Tax or Alien is better explained by the conceptual claim. The authority argument applies to standards reasons. As such it applies to Olson's new form of epistemic reductionism. This constitutes my first response to Olson. ${ }^{52}$

The second response is to point out that it seems plausible that one can tell a story for moral reasons that is analogous to the one Olson tells regarding epistemic reasons. Olson argued against this by claiming that no function of moral judgements (qua moral judgements) could support any kind of view of moral reasons since moral reasons are so wide ranging. ${ }^{53}$ Firstly, as seen in $\S 5$, there is evidence that epistemic reasons also include reasons for actions and reasons for attitudes other than, and including, belief. ${ }^{54}$ This is not the key disanalogy Olson needs. Secondly, Olson claims that it is the irreducibly normative nature of our moral judgements that make it possible for them to fulfil their function of social co-ordination. It is unclear why this is true for the moral case but not the epistemic. The authority argument applies in the epistemic case also.

Here Olson relies on his functional story. The notion of function Olson uses in the epistemic case is not meant to be a fundamentally normative one - otherwise epistemic reasons would be irreducibly normative. Rather the idea is that beliefs have a biological function which can be explained with a descriptive evolutionary story: having correct beliefs about the world helps us to navigate it and therefore to survive and reproduce.

There is reason to doubt whether the function of belief is, in fact, to accurately represent reality. ${ }^{55}$ Putting this aside, however, it seems that an evolutionary story regarding function can be crafted for moral claims too. The function of moral judgements is to help social coordination and co-operation. For example, consider the maxim: one should not break promises.

\footnotetext{
${ }^{51}$ One might be unconvinced by this and think that hypothetical reasons are a species of standards reasons too. This would not threaten the overall argument since I go on to demonstrate that the authority argument applies to standards reasons.

52 This is an extension of Das' (2017) argument.

53 (2018, p.19).

${ }^{54}$ Mirroring Olson's phrasing (2018, p.19).

${ }^{55}$ Hoffman et al. (2015).
} 
The agreement not to break promises and the condemnation of those who do is plausibly advantageous in an evolutionary sense. An evolutionary story about how this general maxim supports social co-operation is conceivable.

The maxim need not be irreducibly normative either. It is an open question whether it ought to be that moral judgements promote social co-operation or that agents have reason to ensure that they do. It is evolutionarily advantageous that they do. Yet we are not required to make it so. Olson (2018) points us back to his arguments against Finlay when claiming that it is the irreducible normativity of moral concepts that enable moral judgements to fulfil their function. As we have seen, however, these arguments apply equally to the epistemic case, even with epistemic reasons understood functionally. As such these arguments are no use in arguing for disparity.

Perhaps the point is best put as a challenge. If Olson's (2014) authority argument applies in the epistemic case, then it does not show that the function of belief grounds a certain account of epistemic reasons but that the function of moral judgement doesn't ground an analogous account of moral reasons. If moral and epistemic reasons are structurally isomorphic, then neither does Olson's claim that moral judgments fail to support any particular view of moral reasons because of their breadth. I wish to remain neutral on what the correct evolutionary story is for the development of moral and epistemic norms and so I present a challenge to Olson: explain why such a story of moral reasons is implausible in a way that demonstrates the disparity between moral and epistemic reasons.

We have two arguments against Olson's (2018) disparity response. The first is that functional reasons are not different enough to be immune from the argument Olson himself proposes against the moral reductionist. Olson's authority argument applies to his new account of epistemic reasons. The second is that the claim that an analogous account of moral reasons cannot be created is, at least, under supported.

It may be objected that the function of moral judgements proposed above is significantly less determinate than the function of beliefs. That the function of belief is to track truth makes it clear what our epistemic reasons are. Yet the same is not true in the moral case since the function of promoting co-operation is too amorphous. In response I note that even though *promoting social co-operation* may be an amorphous function it is enough to show that we have at least some moral reasons - like not randomly killing - and the existence of some moral reasons is enough to refute moral error theory. ${ }^{56}$ I now give a diagnosis of Olson's failure and extract a master argument against the Disparity Response.

\section{Diagnosis and the Master Argument}

Olson's arguments for the conceptual claim are not merely arguments against moral reductionism, they are arguments against normative reductionism. A reason is reducible iff it can be reduced to a descriptive claim linking a course of behaviour to either a standard or a desire. Furthermore, reducible reasons are applicable to agents iff they choose to adopt the relevant standard or desire (which they are not obliged to). This explains why reducible reasons are neither categorical, nor queer.

It also explains why the authority argument, as well as others, applies to reductionist accounts. These arguments point out that a reductionist understanding of our moral discourse

$\overline{56}$ Thanks to Bart Streumer for this. 
fails to secure the apparent authority of moral claims. The difficulty is that they apply equally in the epistemic domain. Note that the authority argument for the conceptual claim is not idiosyncratic. Moral error theorists argue for the conceptual claim by presenting an inference to the best explanation. They attempt to show that the best explanation of the relevant mental and linguistic phenomena (i.e. our moral discourse and thought) is that we take moral reasons to apply to us independently of our desires and commitments. This is easily the most prominent strategy for supporting the conceptual claim. ${ }^{57}$

Olson's account of epistemic reasons as functional is an attempt to explain the universal authority of our epistemic claims whilst maintaining that epistemic reasons are reducible. $\mathrm{He}$ does this by relying on the constitutive truth norm of belief: beliefs essentially have the function of carrying correct information (being true) to aid the agent in navigating the world. Since we are all believers, we all have beliefs which are regulated by the functional standards of belief formation. This results in universally applicable, but reducible, epistemic reasons. Since no such functional reasons are available in the moral domain we have the makings of an argument against the Parity Premise.

My analysis of Olson's (2018) account of epistemic reasons gives us reason to think that an analogous functional analysis of moral reasons is equally conceivable. Combined with my reapplication of the authority argument, this refutes Olson's argument against the Parity Premise. Olson was concerned that Finlay's account failed to secure the intuitive authority of the claims involved. Yet the same is true of Olson's (2018) account of epistemic reasons.

Olson (2018) has failed to balance universal applicability with reducibility. To see this, consider this response to his new suggestion: "I agree that beliefs are essentially regulated by the truth norm. But what if I do not wish to believe? Rather I shall shmelieve. Shmelieving, as a practice, doesn't involve regulation by the truth norm."

This response accepts that the standards of belief formation are such that beliefs are well formed iff they are regulated by the truth norm but disengages from the practice of believing. It would be analogous to one accepting that as an outfield soccer player one cannot use one's hands, whilst abandoning the activity of soccer altogether. The waivability of reducible reasons concerned Olson (2014) and it has come back to bite him.

Crucially, this paves the way for the master argument. The very arguments moral error theorists use to motivate the conceptual claim prohibit an appeal to the Disparity Response. One might be tempted to claim that though our epistemic claims are not as authoritative as we thought, this is not concerning. Rather this veneer of authority, this fugitive thought, should be debunked. ${ }^{58}$ This option, however, is unavailable to the moral error theorist. She argues for the conceptual claim by claiming that the best explanation of our moral discourse is that our common-sense conception of moral claims includes the authority platitudes. These arguments apply equally in the epistemic domain. The error theorist, by arguing for the conceptual claim in the moral domain, prohibits herself from adopting epistemic reductionism. ${ }^{59}$

Olson attempted to avoid the master argument by presenting epistemic reasons as a new type of reducible reason which was meant to be immune from arguments like the authority argument. He failed because these reasons are not different enough to enjoy such immunity. Furthermore, he has not shown that moral reasons cannot be presented in the same light. As

\footnotetext{
$\overline{57}$ Consider Joyce (2011, p.527-9), Olson (2014, p.130-135) and Mackie (1977/1990, p.31-5).

${ }^{58}$ Foot's (1972).

59 This can be found in Das (2017).
} 
such, he has given insufficient evidence to suggest that they ground disparity between moral and epistemic reasons.

The moral error theorist's arguments for the conceptual claim prohibit an appeal to the Disparity Response. This is the master argument against Disparity Responses to the epistemic companions in guilt strategy.

\section{Conclusion}

I have presented an argument against the Disparity Response to the epistemic companions in guilt strategy. There are two options in response. One can find a startingly different profile for epistemic reasons that make them immune from arguments like the authority argument. This is what Olson (2018) attempted to do and I have argued that his attempt failed. Alternatively, one can find more fine-grained arguments for the conceptual claim - ones that apply only to moral reasons and not to epistemic reasons.

The epistemic companions in guilt argument only has two premises. I have argued that the error theorist shouldn't reject the Parity Premise. The only other option is to reject the Epistemic Existence premise.

We have reached an impasse - either moral error theory is false or epistemic error theory is true. The epistemic companions in guilt strategy puts serious pressure on the moral error theorist. I have shown that the only way for the moral error theorist to respond is to endorse epistemic error theory - this is the unappealing path the moral error theorist must take.

Open Access This article is licensed under a Creative Commons Attribution 4.0 International License, which permits use, sharing, adaptation, distribution and reproduction in any medium or format, as long as you give appropriate credit to the original author(s) and the source, provide a link to the Creative Commons licence, and indicate if changes were made. The images or other third party material in this article are included in the article's Creative Commons licence, unless indicated otherwise in a credit line to the material. If material is not included in the article's Creative Commons licence and your intended use is not permitted by statutory regulation or exceeds the permitted use, you will need to obtain permission directly from the copyright holder. To view a copy of this licence, visit http://creativecommons.org/licenses/by/4.0/.

\section{References}

Bedke M (2010) Might all normativity be queer? Australas J Philos 88(1):41-58

Brink D (1984) Moral realism and the sceptical arguments from disagreement and queerness. Australas J Philos 62(2):111-125

Broome J (2013) Rationality through reasoning. Wiley-Blackwell, Malden

Cowie C (2014) Why companions in guilt arguments won’t work. Philos Q 64(256):407-422

Cowie C (2016) Good news for moral error theorists: a master argument against companions in guilt strategies. Australas J Philos 94(1):115-130

Cowie C (2019) Morality and epistemic judgement. Oxford University Press, Oxford

Cuneo T (2007) The normative web: an argument for moral realism. Oxford University Press, New York

Cuneo T (2016) Destabilising the error theory. In: Granjer and Schmechtig (ed) Epistemic reasons, norms and goals. De Gruyter, Boston, pp 71-94

Das R (2017) Bad news for moral error theorists: there is no master argument against companions in guilt strategies. Australas J Philos 95(1):58-69

Finlay S (2008) The error in the error theory. Australas J Philos 86(3):347-369

Finlay S (2009) Oughts and ends. Philos Stud 143(3):315-340

Finlay S (2014) Confusion of tongues: a theory of normative language. Oxford University Press, New York 
Fletcher G (2018) Pain for the moral error theory? a new companions-in-guilt argument. Australas J Philos 96(3): 474482

Fletcher G (forthcoming) Dear prudence: the nature and normativity of prudential discourse. Oxford University Press, Oxford

Foot P (1972) Morality as a system of hypothetical imperatives. Philos Rev 81(3):305-316

Garner R (1990) On the genuine queerness of moral properties and facts. Australas J Philos 68(2):137-146

Glüer-Pagin K, Wikforss $\AA$ (2017) Reasons for belief and normativity. In: Star (ed) Oxford handbook of reasons and normativity. Oxford University Press, Oxford

Hoffman D, Singh M, Prakash C (2015) The interface theory of perception. Psychon Bull Rev 22(6):1480-1506

Joyce R (2001) The myth of morality. Cambridge University Press, Cambridge

Joyce R (2011) The error in 'the error in the error theory. Australas J Philos 89(3):519-534

Kearns S, Star D (2009) Reasons as evidence. In: Shafer-Landau (ed) Oxford Studies in Metaethics 4. Oxford University Press, Oxford, pp 215-242

Kelly T (2003) Epistemic rationality as instrumental rationality: a critique. Philos Phenomenol Res 66(3):612640

Kelly T (2007) Evidence and normativity: reply to Leite. Philos Phenomenol Res 75(2):465-474

Leite A (2007) Epistemic instrumentalism and reasons for belief: a reply to Tom Kelly's "Epistemic rationalist as instrumental rationality: a critique”. Philos Phenomenol Res 75(2):456-464

Mackie J (1946) A refutation of morals. Australas J Psychol Philos 24(1-2):77-90

Mackie J (1990) Ethics: inventing right and wrong. Penguin Books, London originally published 1977

Manne K (2014) Internalism about reasons: sad but true? Philos Stud 167(1):89-117

Olson J (2011) In defense of moral error theory. In: Brady (ed) New waves in metaethics. Palgrave Macmillan, Basingstoke, pp 62-84

Olson J (2014) Moral error theory: history, critique, defence. Oxford University Press, New York

Olson J (2018) Moral and epistemic error theory: the parity premise reconsidered. In: McHugh, Way, Whiting (eds) Metaepistemology. Oxford University Press, Oxford

Parfit D (2011) On what matters. Oxford University Press, New York

Rowland R (2013) Moral error theory and the argument from epistemic reasons. J Ethics Soc Philos 7(1):1-24

Scanlon TM (1998) What we owe to each other. Harvard University Press, Cambridge

Streumer B (2017) Unbelievable errors: an error theory about all normative judgements. Oxford University Press, New York

Williams B (2004) Truth \& truthfulness: an essay in genealogy. Princeton University Press, Princeton

Publisher's Note Springer Nature remains neutral with regard to jurisdictional claims in published maps and institutional affiliations. 